\title{
Preparing a rock sample to Rietveld analysis: What is the best grinding method?
}

\author{
Freitas, B. A. ${ }^{1}$; Silveira, C. S. ${ }^{2}{ }^{*}$; Resende, J. A. ${ }^{3}$;Azeredo, R. B. V. ${ }^{4}$ \\ ${ }^{1}$ Chemistry Institute - UFF, Niterói, RJ, Brazil \\ ${ }^{2}$ Geochemistry Department, Chemistry Institute - UFF, Niterói, RJ, Brazil \\ ${ }^{3}$ Inorganic Department, Chemistry Institute - UFF, Niterói, RJ, Brazil \\ ${ }^{4}$ Organic Department, Chemistry Institute - UFF, Niterói, RJ, Brazil \\ *carla@geoq.uff.br
}

\begin{abstract}
The quantification of phases in rock samples is a useful and important subject in geology. However, due to complexity of the method and proper sample preparation Rietveld refinement techniques are not yet widespread. Therefore, the goal of this study is to test rock sample preparation for Rietveld refinement to obtain trustworthy mineralogical quantification results. Samples of pure quartz $\left(\mathrm{SiO}_{2}\right)$ and calcite $\left(\mathrm{CaCO}_{3}\right)$ were ground for different times $(10 \mathrm{~min}$ to $35 \mathrm{~min}$ ) using different techniques (manual, $10 \mathrm{~mm}$ and $20 \mathrm{~mm}$ agate balls milling and micronization). Latter, a known amount of these minerals (1:1) was mixed. Cristal granulometric distribution was measured (laser particle analyser-CILAS 1064) and difraction analysis (Bruker D8 Advance) was done. The refinement (GSAS) used background, shft, GV, LX trns and cell unit. Calcite samples were always finer than quartz for the same treatment due to their lower hardness and showed preferred orientation. Silt $(64-2 \mu \mathrm{m})$ and clay $(<2 \mu \mathrm{m})$ fraction constituted more than $60 \%$ of the sample when grinding $(20 \mathrm{~mm}$ ball) was associated with micronization (total time $35 \mathrm{~min}$ ). The Rietveld refinement $X^{2}$ for all samples ranged between 1.55 and 4.25. A trend $\left(\mathrm{R}^{2}=0.37\right)$ between $\mathrm{R}_{\text {Bragg }}$ and fine material (silt + clay fraction) was seen. The best procedure was the 20 min grinding with $10 \mathrm{~mm}$ balls and the mixture sample (1:1) gave the results $48.7 \%$ of quartz and $51.3 \%$ of calcite.
\end{abstract}

